\title{
The Charged Classroom: Predicaments and possibilities for democratic teaching, by Judith L. Pace
}

London: Routledge, 20I5, I36pp., $£ 28.99$ (pbk), ISBN: 978-0-4I5-73665-7, £26.09 (e-book) ISBN: 978-|-3|5-8|835-|

This books sets out to explore the reality of teaching social studies within a broader commitment to some form of democratic education. Pace's vision of democracy is firmly rooted in the Deweyan tradition, and she is particularly interested to explore the potential of schooling to promote ways for people to live together and learn from one another. This requires a commitment to acknowledge a range of values and identities, to accept their legitimacy, and an open-mindedness to learn from others. As such, the social studies classroom presents itself as a forum through which young people can acquire knowledge of the diverse democracy (and wider world) in which they live, and through which they can engage in processes of collaboration, enquiry and reflection that embody the advantages to be gained through diversity. Despite these theoretical advantages, Pace's starting point is that, in practice, such 'democratic purposes are neglected in public schools' (8), and her research is aimed at helping to explore the reasons for this disjuncture.

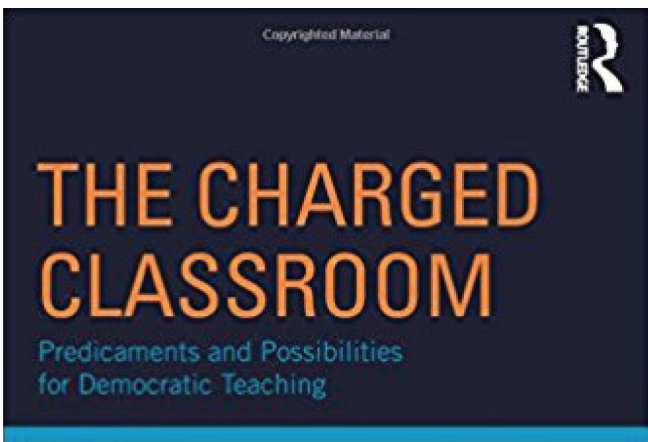

Judith L. Pace

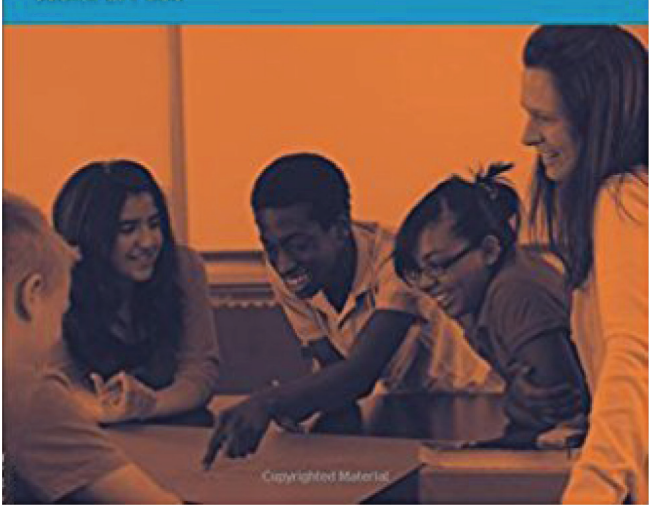

In order to frame this exploration, Pace adopts the central idea of the classroom as a 'charged' arena, by which she means a space 'suffused with contradictions that create both friction and potential' (4). In exploring these tensions, Pace draws on three qualitative studies of classrooms spanning grades 4 to 12 . She employs transcripts of classroom talk, observational notes of classroom interactions and interviews with teachers to consider three specific types of tension: how teachers establish academic expectations, how they discuss controversial issues and how they navigate curricular demands. Having set out this broad context in Chapter I, Chapters 2 to 4 take each of these tensions in turn.

In Chapter 2, Pace considers the challenge of communicating academic expectations in contexts where many students currently experience low attainment. Simply demanding higher standards poses 'unwanted risks, demands and threats' (23) to students' own self-esteem and to teachers' legitimacy, and this can lead to a kind of uneasy 'bargain' in which demands are reduced by the teacher in exchange for a grudging compliance. By contrast, Pace argues, teachers need to explore ways to increase such demands, and this requires them to adopt a carefully calibrated set of 'face work' activities to ensure students (and teachers) do not risk losing face in the classroom. Pace's observations lead her to argue that this balance is easier to achieve in higher attaining classes, and that in classes with lower attaining (and often more diverse) students, teachers tend to adopt strategies that present higher levels of face threats, and thus lead to heightened levels of anxiety, and potentially fuel stereotypes about underachieving groups. This 
analysis leaves the root causes of such disparities unexplored, but certainly opens up the 'black box' of the classroom to help explain why policymakers' demands for a 'no excuses' culture and higher teacher expectations have the potential to backfire and require intense emotional labour in the classroom.

In Chapter 3, Pace argues that dialogue is an essential part of a healthy democracy, and that schools are well placed to promote exploratory discussion around controversial and sensitive issues. However, she also notes that teachers in diverse contexts often find such discussions particularly anxiety inducing because of the perceived dangers of upsetting students and generating conflict. Whereas Pace drew on Goffman to talk about 'face work' in the previous chapter, here she draws on Bakhtin's work on 'heteroglossia' to 'conceptualise the multivoiced plurality of discourse' (47). Pace contrasts monologism (characterized by authoritative speech embodying a singular truth) with dialogism (including diverse voices with multiple interpretations). This commitment to dialogism resonates with her earlier account of Deweyan democratic communication but in turning to the classroom practicalities of dialogism, Pace notes there is tension between the free exchange of ideas and teachers' need to maintain authority. She argues that discussion can become distorted so that the classroom appears to be a dialogic environment while in reality students 'ventriloquate' the teacher's authoritative voice (48). Pace's data from the three classrooms illustrate the complex ways in which authority and identity are played out in practice, and also illuminate the ways in which opening up such discussions can lead to very different social experiences and educational outcomes.

In Chapter 4, Pace turns to the third of her tensions and considers how teachers navigate the competing demands of the curriculum. Here she draws again on the notion of heteroglossia and argues that there are always tensions between centralizing and decentralizing voices. In her case study classrooms, these tensions are variously characterized as meaning-making versus technical standards (in the study of literature); content standards versus creativity (in history); and structure of the text versus thinking about history. Pace's account in Chapter 5 of a 'Renaissance Ball' project demonstrates how activities designed to engage and motivate students may fail to challenge students to extend their thinking. She concludes, reflecting on her teacher interviews, that one of the root causes of these problems is teachers' lack of subject knowledge, which means they do not always know how to promote deeper learning in these subjects.

This emerges as a stronger point in the concluding chapter, where Pace draws out some of the implications of her work. She argues that teacher development is woefully inadequate in preparing teachers for these complex and challenging issues, and that there are also inadequate opportunities to support teachers to deepen their practice throughout their careers. She argues that policymakers need to embrace the complexity of teaching in terms of establishing effective relationships with learners, maintaining authority and reconciling competing curricular demands for students' independence, creativity, cooperation and common knowledge standards. This leads her to argue that policymakers concerned to raise standards need to pay more attention to the implementation processes, so that teachers are supported rather than left to feel as though they are individually accountable for squaring the circle.

In a world where simplistic teaching tips and prescriptions for 'teaching like a champion' are propounded, this book represents a refreshing engagement with the unresolved (and unresolvable) tensions experienced by teachers, especially those working in schools where students are underachieving, and in communities adversely affected by persistent economic, social and educational inequalities. While the book provides no answers about why these inequalities persist, or what teachers should do to eradicate them, it does set out clearly why teaching is more complex and nuanced than many policymakers and educational gurus would like to admit. This account of the frustrating reality of the classroom has the smack of authenticity, which is 
an important attribute for qualitative research on teachers' work. Pace's refusal to offer a more comforting solution further demonstrates the authenticity of her approach. There are no easy answers, just the constant struggle to reflect, understand and improve. Pace's work in schools provides a thought-provoking example of the potentially valuable role of such professional conversations in those struggles.

Lee Jerome

Middlesex University

I.jerome@mdx.ac.uk 